\title{
Design and Implementation of Android-Based Autonomous Human Tracking Vehicle
}

\author{
Meral Özarslan YATAK ${ }^{1}$, Batuhan GÖKTAŞ ${ }^{2}$, Fecir DURAN $^{3}$ \\ ${ }^{1}$ Elektrik-Elektronik Mühendisliği Bölümü, Gazi Üniversitesi, Ankara, Türkiye \\ ${ }^{2}$ Bilgisayar Öğretmenliği Bölümü, Gazi Üniversitesi, Ankara, Türkiye \\ ${ }^{3}$ Bilgisayar Mühendisliği Bölümü, Gazi Üniversitesi, Ankara, Türkiye \\ ozarslanm@gazi.edu.tr, fduran@gazi.edu.tr, batuhangoktas@ hotmail.com.tr \\ (Geliș/Received: 29.09.2017; Kabul/Accepted: 08.03.2018) \\ DOI: $10.17671 /$ gazibtd.340566
}

\begin{abstract}
Design and properties of an Android-based autonomous human tracking vehicle have been presented in this paper. The vehicle was developed by using $3 \mathrm{G}$ technology with smartphone. The aim of this paper is to implement a low cost, user friendly and real time autonomous human tracking system for unmanned ground vehicle. The real-time vehicle control and transmission of the captured image were realized by connecting to the user's smartphone from the smartphone on the vehicle. Autonomous human tracking was provided by the "Follow" button. The vehicle was controlled by the user remotely. A cost effective system was realized by XMPP (Extensible Messaging and Presence Protocol)) protocol and using minimum hardware. In addition, unnecessary power consumption was prevented through the developed software with the accelerometer by detecting the vehicle condition. Performance tests were on command and image transmission. Average time delay of the commands from the user smartphone to the smartphone on the vehicle was measured as 240 milliseconds and the time delay of the commands from the smartphone on the vehicle to the user smartphone was measured as 158 milliseconds.
\end{abstract}

Keywords - 3G Mobile, Communication, Mobile Robots, Android.

\section{Android Tabanlı Otonom İnsan Takip Aracı Tasarımı ve Gerçekleştirilmesi}

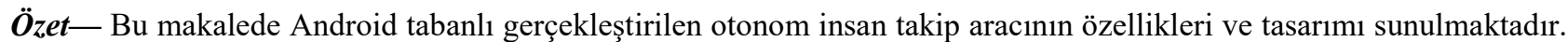
Çalışma akıllı telefon ile 3G teknolojisi kullanılarak geliştirilmiştir. Çalışmanın amacı, insansız kara taşıtları için, ucuz, kullanıcı dostu ve gerçek zamanlı bir otonom insan takip sistemi gerçekleştirmektir. Gerçek zamanlı araç denetimi ve yakalanan görüntünün aktarımı araç üzerindeki telefondan, kullanıcının akıllı telefonuna bağlantı yapılarak gerçekleștirilmiștir. Otonom insan takibi "Takip" butonu ile sağlanmaktadır. Gerçekleștirilen takip aracı kullanıcı tarafından uzaktan denetlenmektedir. XMPP protokolü ve minimum donanım gereçleri kullanılarak, uygun maliyetli bir sistem gerçekleş̧irilmiştir. Ayrıca, gereksiz güç tüketimi, ivme-ölçer ile aracın durumu algılanarak geliştirilen yazılım ile önlenmektedir. Komut ve görüntü iletiminde sistemin performans testleri yapılmıştır. Kullanıcıda bulunan akıllı telefonundan araç üzerindeki akıllı telefona gönderilen komutların ortalama gecikme süresi 240 milisaniye ve araçtaki akıllı telefondan kullanıcı akıllı telefonuna gelen komutların gecikmesi 158 milisaniye olarak ölçülmüsstür.

Anahtar Kelimeler-3G Mobil, Haberleşme, Mobil Robotlar, Android.

\section{INTRODUCTION}

Security applications such as superintendence, road safety, unmanned ground or aerial vehicles, and human-computer interactions require human tracking and detecting. An increase in robots and communication technology has led researchers to study on these systems.
Human tracking can be realized with many tools such as a camera, a laser scanner, a PIR sensor, an ultrasonic sensor, a position sensing device (PSD), and similar mechanisms. Using a laser scanner for human tracking can be conducted with coordinate transformation between the environment coordinate and the robot coordinate [1]. When the disparity image is obtained from a stereo camera and the Hu moment is used as a human detecting algorithm, an extended 
Kalman Filter can be used and high performance can be supplied [2]. An alarm service can be activated after analyzing the human actions. Kwak and Song implemented a system similar to this and achieved good results in terms of action recognition and alarm service [3]. Fan et al. tracked human and objects by using Convolutional Neural Networks (CNNs) [4]. Salem et al. implemented an adaptive system for detecting and tracking human footsteps and vehicles from mobile devices. They enabled powerful optimization of trade-offs among energy consumption, real-time performance, and tracking accuracy based on time-varying changes in operational characteristics [5]. Lu and Payandeh [6] proposed a novel hybrid visual tracking system with a stationary camera and a pan/tilt/zoom (PTZ) camera. These two cameras are geometrically related by camera calibration, so that the PTZ camera "knows" how to pan, tilt, and zoom in order to fit the target in its view. Adinandra and Erfawan [7] proposed a platform for vision based manipulator control that consists of used smartphone, hobbyist servo motors, custom robot links, and Android operating systems. They used a custom Android application based on OpenCV so that the center of the object could be detected. In our study, we used OpenCV for tracking the objects. OpenCV is optimized in order to benefit multi-core processor properties with adequate speed and efficiency for real time applications.

Different communication techniques are used for object and human tracking process. Human mobility and tracking were achieved with GPRS and GPS on a smartphone by Gupta and Reddy [8]. They implemented the system working in two phases as tracking and mapping phases.

Detecting and tracking human automatically with a sensor or an algorithm used in unmanned ground vehicles (UGVs) is a challenging problem due to the wide variety of positions. Stationary human may move at any time and it is problem for tracking human with UGVs. An UGV does not include any human factors either on or in the vehicle and can be managed autonomously or remotely. It is used under conditions in which human intervention is impossible, dangerous, or inconvenient. Dong et al. implemented an UGV path tracking by using a field programmable analogue array (FPAA) and conventional digital microcontroller [9]. They used PID algorithm to control the machine, which resulted in approximately $38 \%$ fewer tracking errors. The system with FPAA was $22 \%$ faster than a classic digital controller (MC68HC11). Paillat et al. [10] designed a robot prototype that belonged to the variable geometry single-tracked vehicle category. The absolute goal was to build a robot as small as possible with the highest obstacle-clearing capability. They evaluated the existing experimental and commercial robots in their study and discussed their clearing capabilities.

There have been some studies on autonomous human tracking functions, to increase speed, and to reduce errors by using different communication technologies, advanced algorithms, and advanced technology. The communication tools are GSM, Wi-Fi, Bluetooth, radio control, GPRS, 3G satellite, and similar technology. Şimşek et al. [11] studied a $3 \mathrm{G}$ controlled car prototype. Real time video transmission was created between the camera on the car and the computer. They achieved about $400 \mathrm{~ms}$ for average delay of real-time videos that sent from the car to the user. They reported from the experiments that the car and the camera could be controlled with high motion capability with low control latencies. There are some special studies on GSM controlled systems. The GSM controlled solar powered vehicle [12], a GSM controlled smart home application [13], control of induction motor parameters and real time monitoring with GSM [14], a solution for public information and transformation [15], a vehicle tracking system [16], and an intelligent parking system [17] are just some examples. Wi-Fi, Bluetooth, or radio control communication may be insufficient because of their low band width and limited communication distance. The satellite control systems are very expensive, despite of their long distance coverage. There is no distance limit for GPRS communication; however, its bandwidth is low. $3 \mathrm{G}$ communication has overcome all of these disadvantages. In addition to its low cost, it is suitable for long distance. $3 \mathrm{G}$ is particularly used in applications that require fast data transfer on mobile devices because it is based on data transfer instead of voice transfer. In this study, we used GSM based communication because GSM modems have removed the technical restrictions.

Android is a software package used on mobile devices and it contains an intermediate layer, key applications, and an operating system. Android gives users the opportunity to develop many applications, thanks to the open-source structure and ARM architecture. It can be used as a wireless monitoring and control system [18], a smart home system [19], real time wireless data logger [20], real time land policy assistance (easier fieldwork) [21], and an educational assistant system [22].

In this study, an autonomous human tracking system, which can also be used as an unmanned ground vehicle is developed. This system performs the following tasks: transmitting the commands from users to the vehicle via smart phone, transferring data and images from the vehicle to the users and tracking human autonomously. To optimize cost and the ability to operate from a distance, an Android operating system and $3 \mathrm{G}$ communication were used. Especially hardware design sections of a cost effective, user friendly and real time Android autonomous human tracking vehicle was aimed in this study. The system was implemented with two smart phones, with a cost of about $\$ 53$ hardware by using open source programs.

\section{SYSTEM HARDWARE DESIGN}

Communication system of the developed Android-based autonomous human tracking vehicle is seen from Fig.1. The commands from the user at distance are transmitted on the server to the phone on the vehicle. The data and the images from the vehicle are transferred to the user device. 
The developed system consists of a device with an Android operating system on the vehicle, an Android phone for the user, an IOIO board supplying communication between the vehicle and the mobile device, and the electronic hardware for the movement.

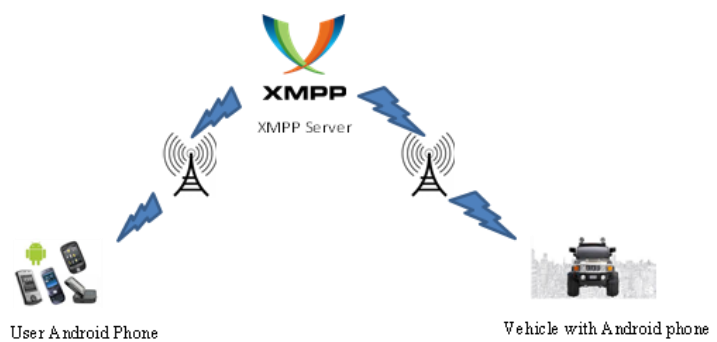

Figure 1. Communication structure of autonomous UGV controlled with $3 \mathrm{G}$ based Android phone

Android IOIO board establishes a connection between an Android device and external world and it provides a wide range of applications with the support of digital input/output, I2C, SPI, and UART. Android IOIO board used in the system can be seen in Fig. 2. The smartphone on the vehicle provided the commands for Android IOIO board to guide the vehicle. The smartphone realized this process by analyzing the values from the control device. Some values sent from the user and the functions of these values are shown in Table I.

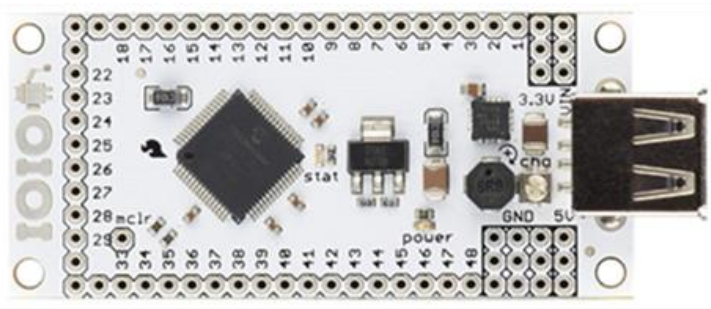

Figure 2. Android IOIO board

Table 1. Transferred data to the vehicle and their functions

\begin{tabular}{|c|l|l|}
\hline Value & \multicolumn{1}{|c|}{ User Display } & \multicolumn{1}{|c|}{ Operation } \\
\hline 1 & Forward Button & $\begin{array}{l}\text { Forward movement of the } \\
\text { vehicle }\end{array}$ \\
\hline 2 & Backward Button & $\begin{array}{l}\text { Backward movement of the } \\
\text { vehicle }\end{array}$ \\
\hline 3 & $\begin{array}{l}\text { To Left Forward } \\
\text { Button }\end{array}$ & $\begin{array}{l}\text { Left forward movement of the } \\
\text { vehicle }\end{array}$ \\
\hline 4 & $\begin{array}{l}\text { To Right Forward } \\
\text { Button }\end{array}$ & $\begin{array}{l}\text { Right forward movement of the } \\
\text { vehicle }\end{array}$ \\
\hline 5 & $\begin{array}{l}\text { To Left Backward } \\
\text { Button }\end{array}$ & $\begin{array}{l}\text { Left backward movement of } \\
\text { the vehicle }\end{array}$ \\
\hline 6 & $\begin{array}{l}\text { To Right Backward } \\
\text { Button }\end{array}$ & $\begin{array}{l}\text { Right backward movement of } \\
\text { the vehicle }\end{array}$ \\
\hline 7 & Stop Button & Stopping the vehicle \\
\hline 9 & Camera Start Button & Importing camera image \\
\hline 10 & Camera Stop Button & Stopping camera image \\
\hline 11 & $\begin{array}{l}\text { Buthorization Start } \\
\text { Button }\end{array}$ & Starting human tracking \\
\hline 12 & Horn Button & Stopping human tracking \\
\hline 13 & Test Button & Horn volume on the vehicle \\
\hline & &
\end{tabular}

When the vehicle to be driven with received commands, the IOIO card connects to the device and activates motor drivers. These occur with help of the software and the movement can start.

In this study, commands from Android IOIO board are evaluated and a signal is transferred to a L293D motor driver circuit. The L293D motor driver was preferred because this driver can actuate two motors in a forwardbackward direction at the same time. On the L293D, external high-speed output clamp diodes for inductive transient suppression are integrated to reduce system complexity and overall system size. The connection form of the driver on the vehicle can be seen in Fig. 3. The connection form of the Android IOIO board can be seen in Fig. 4.

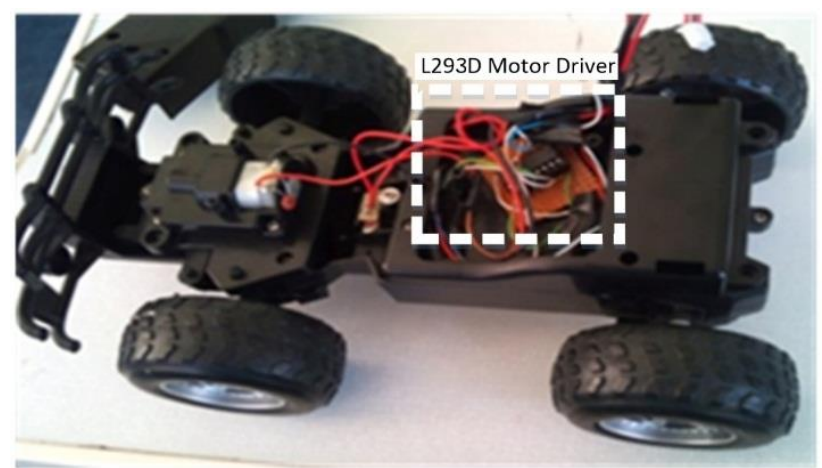

Figure 3. Connection of L293D motor driver on the vehicle

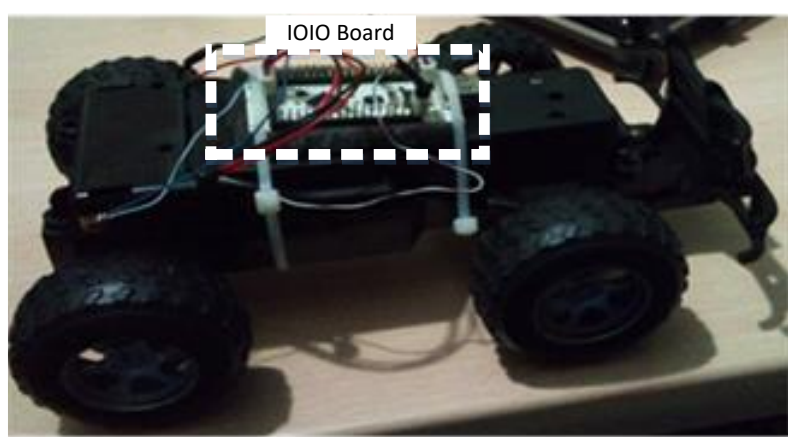

Figure 4. Connection of Android IOIO board on the vehicle

The connection between the smartphone and the Android IOIO board is provided with the universal serial bus (USB) cable. Security and reduced energy consumption considerations are taken into account. The USB has some advantages like high transmission speed, plug-and-play and hot swapping, and has become the most popular interface standard for peripheral connections [23]. The developed vehicle with Android smartphone can be seen in Fig. 5 in its ready-to-use final form. 


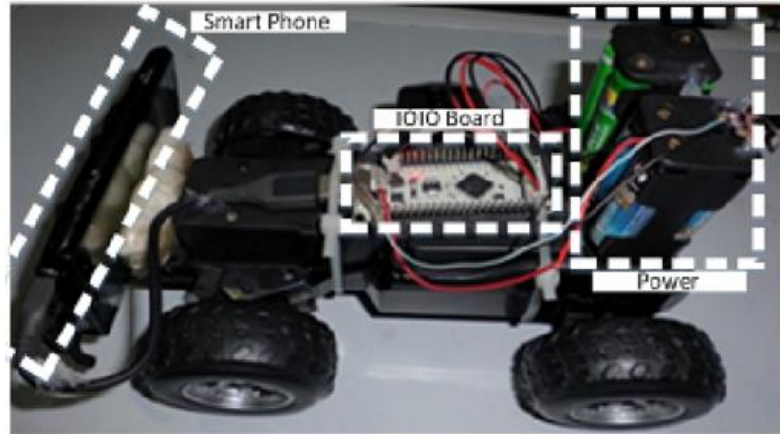

Figure 5. Final version of the developed ready to use vehicle

\section{SYSTEM SOFTWARE DESIGN}

Remote control and/or autonomous human tracking were achieved with the developed software by using an Android based smartphone on the vehicle and by the user. Object tracking is implemented with OpenCV (Open Source Computer Vision) library, introduced to the develop software on the vehicle. OpenCV was designed for computational efficiency and with a strong focus on realtime applications. Written in optimized $\mathrm{C} / \mathrm{C}++$, the library can take advantage of multi-core processing. There are digital data formed with human sample on the vehicle software to track humans.

OpenCV offers a list of function to extract the contours of the connected components of an image. Object detection on Android involves the following steps [24]:

- A binary image is produced using thresholding method

- Morphological opening and closing filters are used in sequence for object detection

- Contour based learning technique is used for drawing the contours for the objects detected and extracting them for further analysis

Android is an open source Linux-based mobile operating system that was developed by Google, Open Handset Alliance, and the free software community for mobile devices and mobile phones.

In our study, the device on the vehicle is a smartphone with an Android 2.3 Gingerbread. Programming of the devices with Android OS was realized in an Eclipse free, open source, integrated development environment (IDE) with Java. The user control device was a smartphone with Android OS and 3G connection.

A data transfer should be conducted between the smartphone on the vehicle and the user smartphone. This communication was realized with XMPP. This is an open XML protocol and technology that allows any structural data to transmit mutually and almost simultaneously between the two ends of the Internet. It has an independent operation structure from the operating system and due to this property, the vehicle can be controlled on all operating systems. Not requiring a static IP and the ability to obtain it free from many servers are some advantages of XMPP.

The only procedure for the smartphone application on the vehicle is to open the application and implement the communication with "Setup" button on the form as seen from Fig. 6.

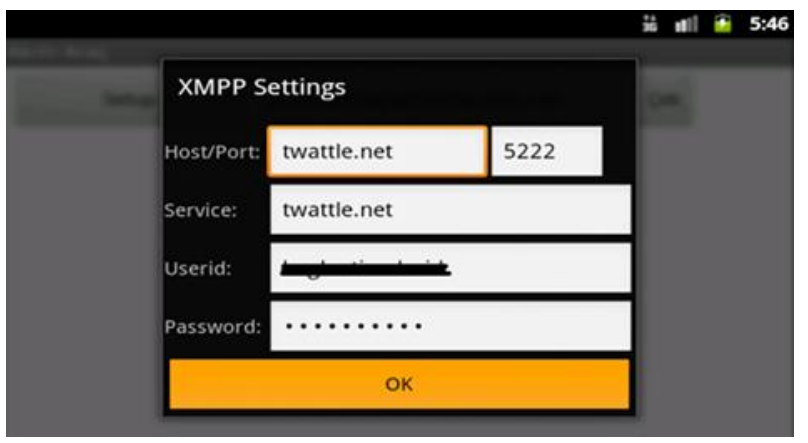

Figure 6. Smart device Setup Menu

XMPP server connection is established with the Setup button from the user information section. The commands defined with the help of screen buttons (1-9, A-C, PRMT, camera) are transferred to the client address that is connected to the vehicle. Once the connection is established, driving is carried out by sending Forward, Back, Right, Left commands. Driving is also done by sending the same commands with phone movements with the help of the accelerometer sensor. The Steering Wheel $\mathrm{On} / \mathrm{Off}$ button on the screen is used to activate this sensor.

\section{IMPLEMENTED HUMAN TRACKING SYSTEM}

The vehicle uses OpenCV image processing library for tracking when it assumes the authority of autonomous movement from the user who controls the vehicle. There are digital data obtained human image sample for human tracking with the software on the vehicle. The human samples to be tracked are converted into digital data for this process. The data are kept in records in xml format. After assuming the authority, the device ensures the detection of the human by comparing the sample data in $\mathrm{xml}$ format with the image data from the camera. In addition to taking the image into the square (as seen from Fig. 7), adequate direction detection can be done for the motor drivers according to the position on the camera image. In this way, the moving human can be tracked. The tracking process continues until the authority of autonomous movement is stopped on the device in the control point. The software image of the smartphone on the vehicle during tracking can be seen in Fig. 8 . 


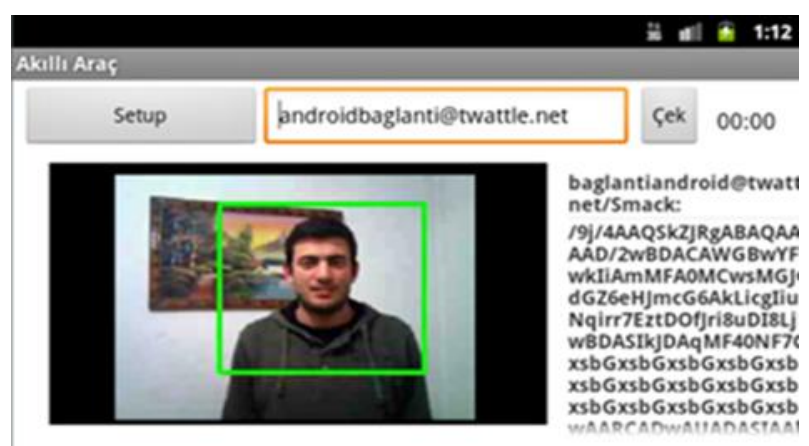

Figure 7. The software image on the vehicle while tracking

At the control point, a smartphone with Android OS was used to determine the authority process providing autonomous direction detection. Movement control is achieved by transferring data in Table 1 to the smartphone on the vehicle.

Image of the device receives after command(8) is switched on. Then camera image is transformed from image to base64 string format. Human detection in image starts when $\operatorname{Track}(\mathrm{A})$ command is switch on. Human detection using OpenCV with from Vehicle Administration. Scanning the threshold value of human image is determined with FaceSize expressions in OpenCV. The device analyzes the human data on the image in more detailed as FaceSize value decreases. This is proportional to the device performance. This procedure is done on vehicle smartphone.

The data in the base64 string form of the smartphone camera image on the vehicle are taken with code for taking camera image. The obtained data string is converted into image form with base64 using the bitmap method and this image is displayed on the screen of the control device. Thus, the environment image in which the vehicle is located can be accessed. The obtained image from the environment during the discovery of the vehicle is displayed on the smartphone of the control point, which can be seen in Fig. 8 .

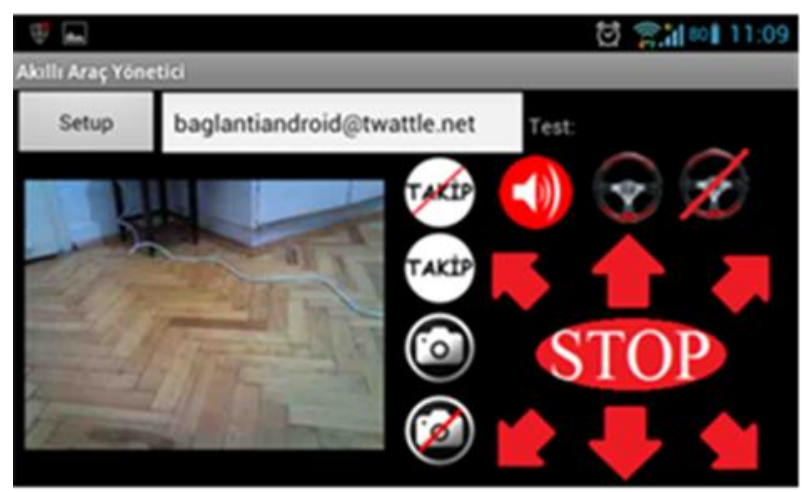

Figure 8 . The software image in control point during discovery
Tracking process of the determined object is realized with the autonomous control authority code. The displayed image of the device in control point during tracking is shown in Fig. 9.

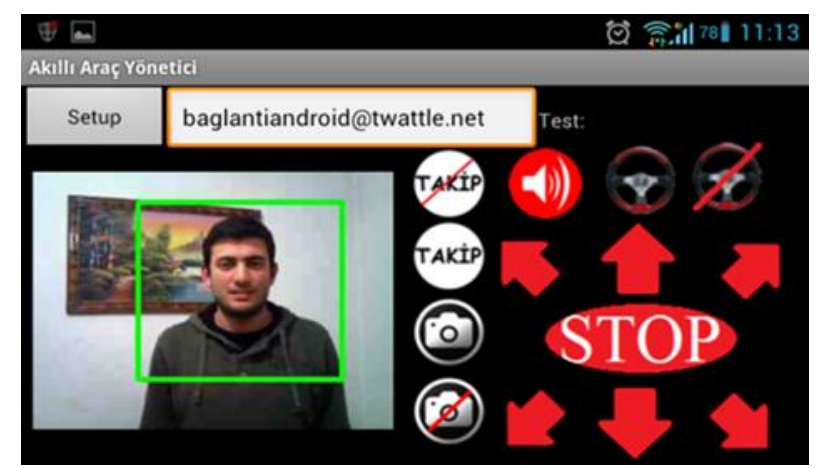

Figure 9. The software image in the control point during tracking

While controlling the vehicle, crashes that can create barriers to movement may occur. In this situation, energy is wasted because the vehicle continues its movement despite the barrier. Zhang et al. realized a remote controlbased Autonomous Collision Avoidance System prototype based on the interoperation of Android and Arduino [25]. When considering that the vehicle has limited energy, the vehicle should be sensitive to avoid crashing to save energy. When the vehicle hits an object, power saving was ensured by disconnecting the power according to the data from the accelerometer sensor of the smartphone on the vehicle.

The threshold values of the Right/Left sensitivity values are created for movement start of the vehicle. This is done with the Settings button on the pop-up menu in the Vehicle Administration Application for tracking the object on the location in the camera. Data position on the captured image on the camera is analyzed for the movement while tracking human. If this position is higher or lower than Right and Left threshold values determined with PRMT, the movement of this direction can be provided by activating the motor driver of that direction. The threshold values were determined manually after experimental works.

\section{RESULTS}

The camera button on the GUI is used for image acquisition from the device on the vehicle. The processes are realized with the commands from the data of defined connected user. The transfer duration of the image has been determined with tests. Test process was realized during 24 hours on 526 samples. The data (image and commands) transfer time to the smartphone on the vehicle was measured with Test command to determine the transmission time of the data between the vehicle and control point. The test of command transmission was implemented bidirectional. Average time delay of the commands from the user smartphone to the smartphone on the vehicle was 240 milliseconds and the time delay of the 
commands from the smartphone on the vehicle to the user smartphone was 158 milliseconds. Time delays may show differences due to the remote control of the vehicle. Time delays also depend on the service provider. It is predicted that the possibility of better control with more sensitive control time can be achieved with dual carrier technology and $4 \mathrm{G}$ technology.

\section{CONCLUSIONS}

In this study, an autonomous human tracking vehicle controlled with a $3 \mathrm{G}$ based Android smartphone was developed. The remote control of a vehicle, image transfer, object tracking, and above all, human tracking were realized.

The developed system works as transferring commands from the user to the device on the vehicle, transferring data and image from the device on the vehicle to the user device and ensuring human tracking according to the authority of the device on the vehicle.

This study was realized with minimum hardware materials and minimum cost. The system was tested on some image and data transfer duration experiments. The vehicle is stopped reactively after a crash. Instead of this model, precautionary model will be used and the crash will be prevented previously. For this design, distance detection should be done and distance sensors should be used for this reason. An enhanced face recognition method will be used instead of the camera image from the phone on the vehicle.

\section{REFERENCES}

[1] D. K. Yoon, Y. S Lee., J. T Seo, S. Gai, B.-J Yi, “Autonomous Human Tracking of Multiple Robotic Lamps", IEEE International Conference on Robotics and Automation, Minnesota, 3567-3572, 2012.

[2] J. Songmin, Z. Liang, L. Xiuzhi, C. Wei, S. Jinbo, “Autonomous Robot Human Detecting and Tracking Based on Stereo Vision", IEEE International Conference on Mechatronics and Automation, Beijing, 640-645, 2011

[3] N. J. Kwak, T. S. Song, "Android-Based Human Action Recognition Alarm Service Using Action Recognition Parameter and Decision Tree", International Journal of Security and Its Applications, 7(4), 277-286, 2013.

[4] J. Fan, W. Xu, Y. Wu, Y. Gong, "Human Tracking Using Convolutional Neural Networks", IEEE Trans Neural Netw, 21(10), 1610-1623, 2010.

[5] H.B. Salem, T. Damarla, K. Sudusinghe, W. Stechele, S.S Bhattacharyya, "Adaptive Tracking of People and Vehicles Using Mobile Platforms" EURASIP Journal on Advances in Signal Processing, 65, 1-12, 2016

[6] Y. Lu, S. Payandeh, "Cooperative Hybrid Multi-Camera Tracking for People Surveillance”, Can J Elect Comput E, 33(3), 145-152, 2008.

[7] S. Adinandra, D. Erfawan, "Yuarm: A Low Cost Android Platform for Vision Based Manipulators Control", $3^{\text {rd }}$ International Conference on Information Technology, Computer, and Electrical Engineering (ICITACEE), Indonesia, 74-78, 2016.
[8] R. Gupta, B. V. R. Reddy, "GPS and GPRS Based Cost Effective Human Tracking System Using Mobile Phones", Viewpoint, 2(1), 39-45, 2011.

[9] P. Dong, G. Bilbro, M. Y. Chow, "Controlling a Path-Tracking Unmanned Ground Vehicle with a Field-Programmable Analog Array", IEEE/ASME International Conference on Advanced Intelligent Mechatronics, California, 1263-1268, 2005.

[10] J. L. Paillat, P. Lucidarme, L. Hardouin, "Original Design of an Unmanned Ground Vehicle for Exploration in Rough Terrain", Advanced Robotics, 24, 255-276, 2010.

[11] M. Şimşek, M. Yoldaş, A. Bulut, İ. A. Doğru, M. A. Akçayol, “3G Tabanlı Uzaktan Kontrol Edilebilen Araç Geliștirilmesi”, Journal of the Faculty of Engineering and Architecture of Gazi University, 27(1), 135-142, 2012

[12] A.S.M.A. Ahmed, L. Alamgir, A. Nayeem, D. Sharma, B. B Pathik, "Devising a Solar Powered Standalone Vehicle Using GSM Communication Network", International Conference on Electrical Information and Communication Technology, Bangladesh, 2014.

[13] K. İnal, M.A. Akçayol, "GSM Tabanlı Akıllı Ev Uygulaması", Bilişim Teknolojileri Dergisi, 2(2), 39-45, 2009.

[14] R. Bayindir, S. Vadi, "Real-Time Monitoring and Control of the Parameters of an Induction Motor", Elektronika Ir Elektrotechnika, 19(10), 145-150, 2013

[15] N. Batarliene, A. Baublys, "Mobile Solutions in Road Transport", Transport, 22(1), 55-60, 2007.

[16] S. Lee, G. Tewolde, J. Kwon, "Design and Implementation of Vehicle Tracking System Using GPS/GSM/GPRS Technology and Smartphone Application", IEEE World Forum on Internet of Things, Seoul, 353-358, 2014.

[17] S. Qin, X. Yao, "An Intelligent Parking System Based on GSM Module”, Appl Math Inf Sci, 7(1), 55-59, 2013.

[18] Z. Huang, Y. Lu, "Wireless Monitoring and Control System via Android Tablet PC", 2nd International Symposium on Computer, Communication, Control and Automation, Singapore, 449-452, 2013.

[19] R.A. Ramlee, M.A. Othman, M.H. Leong, M.M. Ismail, S.S.S Ranjit, "Smart Home System Using Android Application", International Conference of Information and Communication Technology, Bandung, 277-280, 2013.

[20] Z.W Siew, C.H. Wong, S.E. Tan, H.P. Yoong, K.T.K. Teo, "Design and Development of a Tablet Based Real Time Wireless Data Logger", IEEE Global High Tech Congress on Electronics, Shenzhen, 111-116, 2012 .

[21] F.J. Mesas-Carrascosa, I.L. Castillejo-Gonzalez, M.S. de la Orden, A. Garda-Ferrer, "Real-Time Mobile Phone Application to Support Land Policy", Computers and Electronics in Agriculture, 85, 109111, 2012.

[22] G.M. Jeong, C. W Park, S. You,S.H. Ji, "A Study on the Education Assistant System Using Smartphones and Service Robots for Children", Int J Adv Robot Syst, 11(71), 1-9, 2014.

[23] J. Axselson, "USB Complete: The Developer's Guide”, Lakeview Reasearch LLC, United States of America, 2009.

[24] P.C. Dhande, P. Bhople, T. Dorage, N. Patil, S. Daundkar, "Follower Robot Using Android Programming", International Journal of Computer Science and Network, 3(6), 545-553, 2014.

[25] Y. Zhang, X. Zhao, R. Xu, J. Jiang, K. Zhang, "Design and Implementation of a Prototype System for Automatic Obstacle Avoidance Information Collection Vehicle", Computing, Control, Information and Education Engineering, Editors: H. C. Liu, W.P. Sung, W. Yao, CRC Press, London, UK, 77-80, 2015 